\title{
Mecanismo Diseñado y Simulado Virtualmente
}

\section{Mechanism Designed and Simulated Virtually}

\author{
JIMÉNEZ-RABIELA, Homero†*, VAZQUÉZ-GONZÁLEZ, Benjamín, RAMÍREZ-CRUZ, José Luis \\ y GARCÍA-SEGURA, Pedro
} Universidad Autónoma Metropolitana, Unidad Azcapotzalco, División de Ciencias Básicas e Ingeniería, Departamento de
Energía

ID $1^{\text {er }}$ Autor: Homero, Jiménez-Rabiela / Researcher ID Thomson: S-2299-2018, CVU CONACYT ID: 123386

ID $1^{\text {er }}$ Coautor: Benjamín, Vazquéz-González / ORC ID: 0000-0002-9030-5662, Researcher ID Thomson: S-2417-2018, CVU CONACYT ID: 25749

ID $2^{\text {do }}$ Coautor: José Luis, Ramírez-Cruz / ORC ID: 0000-0003-0762-2630, Researcher ID Thomson: G-3405-2019, CVU CONACYT ID: 921268

ID $3^{\text {er }}$ Coautor: Pedro, García-Segura / ORC ID: 0000-0003-4947-084X, Researcher ID Thomson: S-2360-2018, CVU CONACYT ID: 371233

\begin{abstract}
Resumen
Objetivos: Mostrar un proceso para sintetizar y analizar un mecanismo manivela oscilador generador de función. Simularlo en un ambiente de realidad virtual, sin perder sus características físicas. Evaluar las desviaciones entre lo deseado analíticamente y lo obtenido virtualmente. Metodología: Usando el método analítico descrito por Hartenberg y Denavit, un paquete gráfico y una hoja electrónica de cálculo; conociendo el ángulo de rotación de la manivela, la posición angular de referencia de la manivela, el desplazamiento del oscilador, los valores extremos de la variable independiente y la función; se determinaron posiciones de precisión, longitudes de eslabones, excentricidad y la posición de referencia del oscilador. Se generaron los eslabones, se ensambló el mecanismo, analizando quince de sus posiciones. Del número infinito de soluciones existentes, se sintetizaron cinco. Para cada solución que lo justificó, se evaluó la desviación de la función generada con respecto a la deseada. Contribución: Se demostró lo amigable, rápido, seguro, exacto y paramétrico del proceso; modificando las entradas y comprobando la actualización de las salidas; por lo que es una aportación al avance científico del área.
\end{abstract}

Simulación, Mecanismos, Diseño

\begin{abstract}
Objectives: To show a process to synthesize and analyze a crank mechanism oscillator function generator. Simulate it in a virtual reality environment, without losing its physical characteristic. Evaluate deviations between analytically desired and virtually obtained. Methodology: Using the analytical method described by Hartenberg and Denavit, a graphic package and an electronic spreadsheet; knowing the angle of rotation of the crank, the angular reference position of the crank, the displacement of the oscillator, the extreme values of the independent variable and the function; precision positions, link lengths, eccentricity and oscillator reference position were determined. The links were generated, the mechanism was assembled, analyzing fifteen of its positions. Of the infinite number of existing solutions, five were synthesized. For each solution that justify it, the deviation of the generated function was evaluated with respect to the desired one. Contribution: The friendly, fast, safe, accurate and parametric process was demonstrated; modifying the inputs and checking the update of the outputs, therefore it is a contribution to the scientific progress of the area.
\end{abstract}

Simulation, Mechanisms, Design

Citación: JIMÉNEZ-RABIELA, Homero, VAZQUÉZ-GONZÁLEZ, Benjamín, RAMÍREZ-CRUZ, José Luis y GARCÍASEGURA, Pedro. Mecanismo Diseñado y Simulado Virtualmente. Revista de Simulación y Laboratorio 2019, 6-21: 1-11

*Correspondencia al Autor (Correo electrónico: * hjr@azc.uam.mx)

$\dagger$ Investigador contribuyendo como primer Autor 


\section{Introducción}

Se aplicaron herramientas de simulación para diseñar, analizar y evaluar un mecanismo manivela oscilador generador de función, ésta deberá cumplirse en todo el rango de la variable independiente. Considerando que el mecanismo se usará en un instrumento de medición, se seleccionó rango de rotación de la manivela, desplazamiento del oscilador y posición angular de referencia de la manivela. Con el empleo del procedimiento descrito por Hartenberg y Denavit; con $\mathrm{X}$ variando, se determinaron quince de sus valores incluyendo cuatro de precisión, en los cuales la función se debe cumplir sin desviación, se calcularon dimensiones de los eslabones, la excentricidad y la posición del oscilador correspondiente a la posición angular de referencia de la manivela. Se evaluaron ventajas y desventajas de soluciones desde diferentes puntos de vista.

Se planteó la hipótesis de que es posible un proceso amigable, rápido, seguro, exacto $\mathrm{y}$ paramétrico; para diseñar, analizar y evaluar un mecanismo manivela oscilador. Las características grafo-analíticas agregan valor al proceso; su importancia durante este siglo ha propiciado la utilización de herramientas de simulación para diversos fines. En noviembre de 2005 Becker et al argumentaron algunas de sus ventajas apoyándose en un estudio de casos de la industria automotriz europea.

En 2007 Schuler et al presentaron una novedosa herramienta de modeladomanufactura virtual para mecanismos esféricos. En 2012 Alvarez y Su presentaron un entorno virtual intuitivo para fundamentar el diseño conceptual de mecanismos. También en 2012, López et al desarrollaron una herramienta para simular el mecanismo manivela-biela-corredera. En 2015, Robson y Ghosh presentaron resultados virtuales del diseño geométrico de mecanismos planos.

En 2015; Rider, Michael J. mostró el valor agregado de las características grafo-analíticas aplicadas al diseño y análisis de los mecanismos. En 2019; Chamba et al simularon virtualmente el movimiento de un robot hexápodo, Sánchez aplicó realidad virtual al movimiento en dedos, Francisco et al implementaron un recorrido en 3D como fortalecimiento académico y tecnológico. El presente trabajo incluye las secciones siguientes: En la 1 la introducción.
La nomenclatura se define en la 2. Se muestran los cálculos en la 3, diferenciando los parámetros conocidos, de los seleccionados y los de diseño. En la 4 se generan los archivos de eslabones utilizando parámetros para dimensionarlos. Se describe el ensamble del mecanismo en la 5, explicando las restricciones impuestas a sus eslabones. En forma tabular en la 6 se muestra cinco diseños, que cumplen teóricamente con los requerimientos, del número infinito de posibles soluciones existentes. En la 7 se hace un análisis comparativo de los cinco diseños. Se hace una simulación, de aquel con mayores ventajas, en la 8 , incluyendo un número limitado de imágenes de posición. En 9, 10, 11 y 12; se incluyen los resultados, la conclusión, agradecimiento y referencias; respectivamente.

\section{Nomenclatura}

Se usarán los acrónimos: A absoluta, c coseno, D dimensión, E eslabón de entrada, G eslabón fijo, $\mathrm{j}$ una imagen de posiciones cualquiera, $\mathbf{O}$ excentricidad, $\mathrm{P}$ posición, $\mathrm{R}$ repeticiones, $\mathrm{r}$ rango, s seno, $\mathbf{S}$ eslabón de salida, $\mathbf{T}$ eslabón trasmisor, $\mathrm{X}$ variable independiente, $\mathrm{Y}$ variable dependiente; i, 1, B, C, H, 2, K, N, Q, 3, U, V, $\mathrm{W}, 4$, f para las posiciones inicial, uno, $\mathrm{B}, \mathrm{C}, \mathrm{H}$, dos, $\mathrm{K}, \mathrm{N}, \mathrm{Q}$, tres, $\mathrm{U}, \mathrm{V}, \mathrm{W}$, cuatro, final respectivamente. Se definen los parámetros indicados en la Tabla 1; en la cual; la primera columna es el parámetro, la segunda son las unidades y la tercera es el nombre.

\begin{tabular}{|c|c|c|}
\hline $\mathrm{Xi}$ & $\mathrm{mm}$ & Variable independiente, $\mathrm{i}$ \\
\hline $\mathrm{Xf}$ & $\mathrm{mm}$ & Variable independiente, $\mathrm{f}$ \\
\hline DAP1E & deg & Dimensión absoluta de P1E \\
\hline $\mathrm{rE}$ & deg & Rango, E \\
\hline $\mathrm{rS}$ & $\mathrm{mm}$ & Rango, $\mathrm{S}$ \\
\hline $\mathrm{DE}$ & $\mathrm{mm}$ & Dimensión, E \\
\hline DT & $\mathrm{mm}$ & Dimensión, T \\
\hline $\mathrm{O}$ & $\mathrm{mm}$ & Excentricidad \\
\hline P1S & $\mathrm{mm}$ & Posición $1, \mathrm{~S}$ \\
\hline $\mathrm{Xj}$ & $\mathrm{mm}$ & Variable independiente, $\mathrm{j}$ \\
\hline $\mathrm{Yj}$ & $\mathrm{mm}$ & Variable dependiente, $\mathrm{j}$ \\
\hline $\mathrm{P} 1 \mathrm{E}$ & deg & Posición 1, E \\
\hline DAE & $\mathrm{mm}$ & Dimensión absoluta, E \\
\hline $\mathrm{OA}$ & $\mathrm{mm}$ & Excentricidad absoluta \\
\hline DAP1iE & deg & Dimensión absoluta, P1iE \\
\hline P1iE & deg & Posición i respecto a 1, E \\
\hline $\mathrm{P} 1 \mathrm{jE}$ & deg & Posición j respecto a $1, \mathrm{E}$ \\
\hline PijE & deg & Posición j respecto a i, E \\
\hline DAP1iS & $\mathrm{mm}$ & Dimensión absoluta, P1iS \\
\hline P1iS & $\mathrm{mm}$ & Posición i respecto a $1, \mathrm{~S}$ \\
\hline P1jS & $\mathrm{mm}$ & Posición j respecto a $1, \mathrm{~S}$ \\
\hline PijS & $\mathrm{mm}$ & Posición j respecto a i, S \\
\hline $\mathrm{R}$ & $\mathrm{ul}$ & Repeticiones \\
\hline
\end{tabular}

Tabla 1 Nomenclatura

Fuente: Elaboración Propia

JIMÉNEZ-RABIELA, Homero, VAZQUÉZ-GONZÁLEZ Benjamín, RAMÍREZ-CRUZ, José Luis y GARCÍA-SEGURA, Pedro. Mecanismo Diseñado y Simulado Virtualmente. Revista de Simulación y Laboratorio 2019. 
Los parámetros conocidos del proceso son la función, Xi, Xf. Los parámetros seleccionados son DAP1E, rE, rS. Los parámetros de salida o de diseño son DE, DT, O, P1S. Para mayor claridad en relación a la nomenclatura, en la Fig. 1 se muestra la vista general de planta del mecanismo.

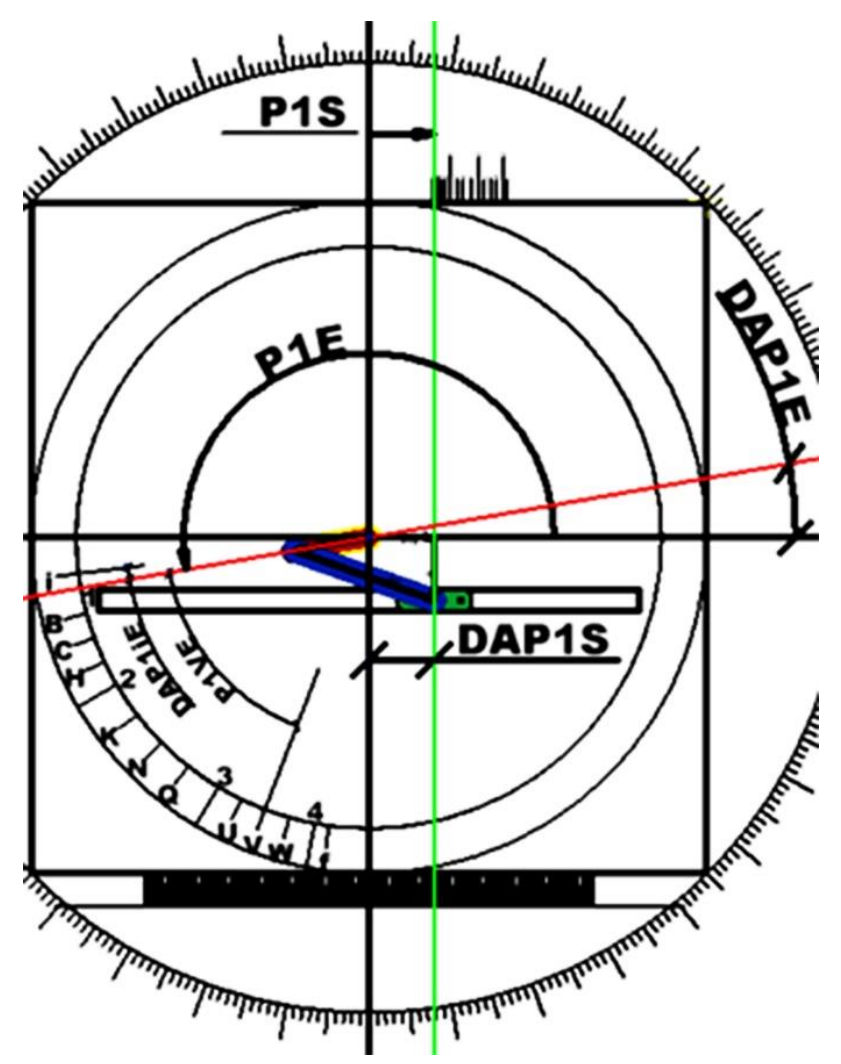

Figura 1 Mecanismo

Fuente: Elaboración Propia

En su parte central están los eslabones incluyendo los vectores usados para la ecuación de cierre de circuito. Su escala angular interior muestra las posiciones del eslabón de entrada. Su escala angular exterior, desde cero hasta 360 grados, tiene trazos radiales de tamaño diferenciado para múltiplos de 1, 5 y 10 grados. $\mathrm{Su}$ escala lineal superior muestra las posiciones teóricas del eslabón de salida, para lograr que la función se cumpla sin error. Su escala lineal inferior tiene trazos de tamaño diferenciado para múltiplos de 1, 5 y 10 milímetros. El eslabón fijo es mostrado en color blanco, el eslabón de entrada en rojo, el eslabón trasmisor en azul y el eslabón de salida en verde. La longitud de la línea roja perteneciente al eslabón de entrada, coincidiendo con su eje longitudinal de simetría, se extiende para indicar la posición actual del mismo con ayuda de las escalas angulares.
Nótese que la posición mostrada del eslabón de entrada, corresponde a su posición 1; la correspondiente posición del eslabón de salida coincide con su posición teórica 1 . Lo anterior sucederá para las cuatro imágenes de posición de precisión. En los eslabones y vectores mostrados en la Fig. 2, el marco de referencia inercial cartesiano está en la intersección de los vectores DE y P1S. Nótese que $\mathbf{O}$ es negativa y P1S es positiva.

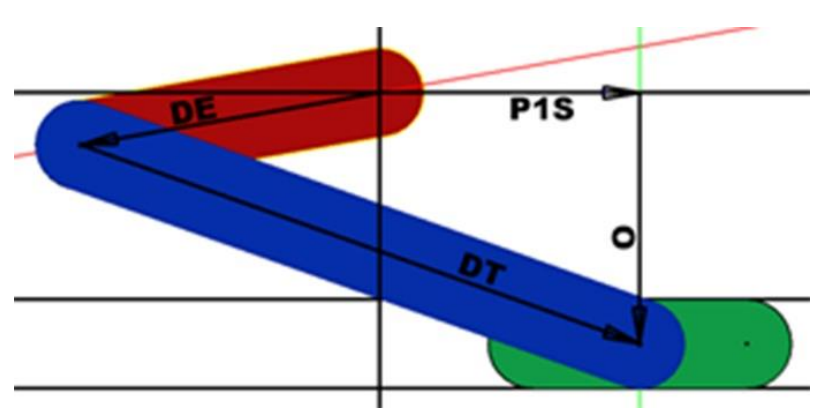

Figura 2 Cierre de circuito

Fuente: Elaboración Propia

En la Fig. 3 se muestra DAP1iE obtenida por un giro negativo del eslabón de entrada a partir de su posición 1. Adicionalmente se muestra P1VE. Para evitar saturar de trazos la figura se omitieron las posiciones relativas de $\mathrm{B}$, $\mathrm{C}, \mathrm{H}, 2, \mathrm{~K}, \mathrm{~N}, \mathrm{Q}, 3, \mathrm{U}, \mathrm{W}, 4$, f con respecto a 1; tales posiciones relativas se obtienen por giros positivos del eslabón de entrada a partir de su posición 1. Nótese que entre dos posiciones sucesivas $(1,2,3,4)$ se incluyen tres posiciones a los cuartos de los intervalos 1-2, 2-3, 3-4. Se consideró una relación lineal entre Xij y PijE.

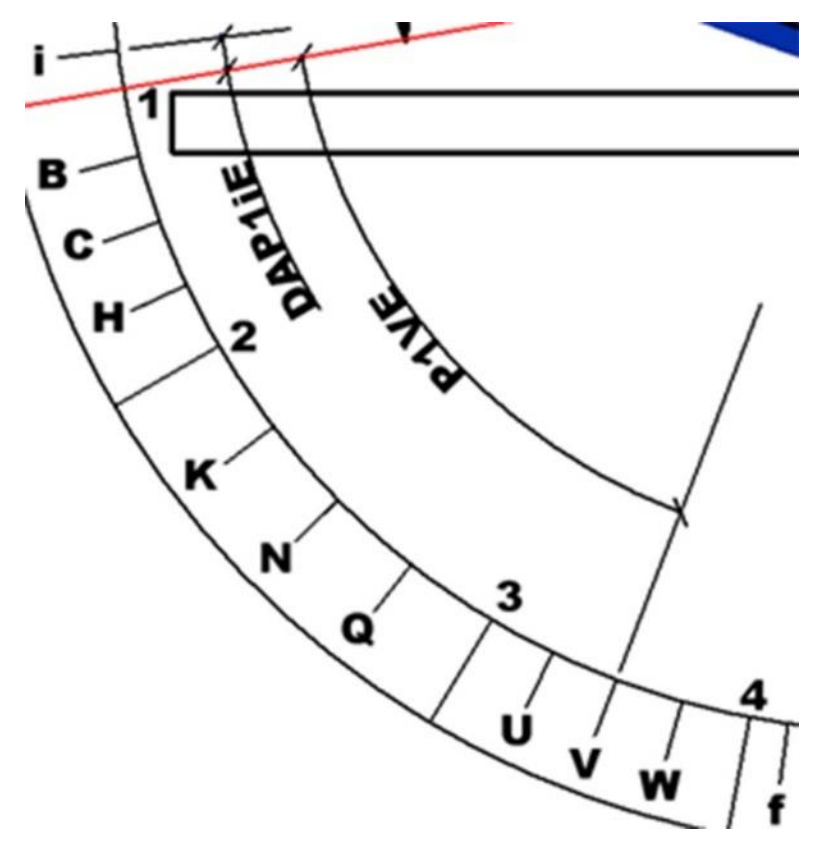

Figura 3 Posiciones de E

Fuente: Elaboración Propia 
En la Fig. 4 se muestra DAP1iS a la izquierda de la posición 1 del eslabón de salida (en verde) y P1VS a la derecha de la posición 1 del eslabón de salida. Para evitar saturar la figura se omitió las posiciones relativas de $\mathrm{B}, \mathrm{C}, \mathrm{H}, 2$, $\mathrm{K}, \mathrm{N}, \mathrm{Q}, 3, \mathrm{U}, \mathrm{W}, 4, \mathrm{f}$ con respecto a 1 ; tales posiciones se obtienen por desplazamientos positivos del eslabón de salida, a partir de su posición 1. Si bien habrá exactitud en las posiciones 1, 2, 3, 4; en las posiciones i, B, C, H, $\mathrm{K}, \mathrm{N}, \mathrm{Q}, \mathrm{U}, \mathrm{V}, \mathrm{W}, \mathrm{f}$ siempre habrá una diferencia entre posiciones teóricas del eslabón de salida, mostradas en la Fig. 4, y su posición real indicada por la línea verde cuando la entrada esté en las posiciones correspondientes. Se consideró una relación lineal entre Yij y PijS.

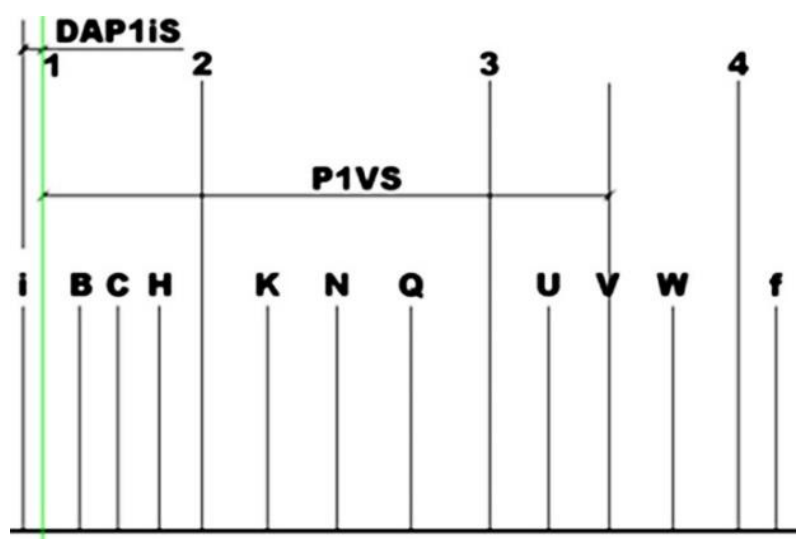

Figura 4 Posiciones de $\mathrm{S}$

Fuente: Elaboración Propia

En la Fig. 5 se muestra la escala angular exterior, se pueden apreciar los tamaños diferenciados de trazos para 1,5 y 10 grados.

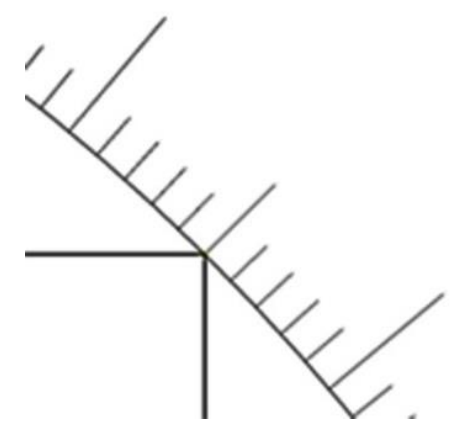

Figura 5 Escala angular exterior Fuente: Elaboración Propia

En Fig. 6 se muestra la escala lineal inferior, se pueden apreciar los tamaños diferenciados de trazos para 1,5 y 10 milímetros.

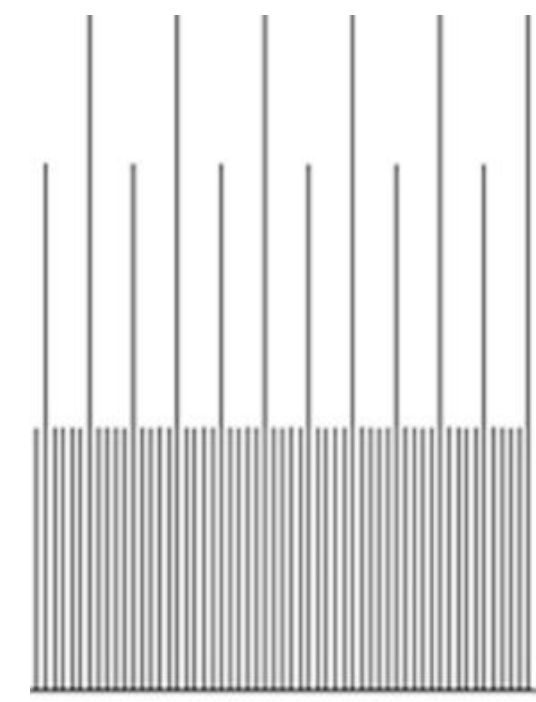

Figura 6 Escala lineal inferior Fuente: Elaboración Propia

\section{Cálculos}

Con los parámetros conocidos (la función, Xi, $\mathrm{Xf}$ ); se selecionaron los parámetros DAP1E, rE y rS; para determinar las posiciones de precisión, aquellas denotadas con letras mayúsculas y los parámetros de diseño (DE, DT, O, P1S). En particular, para las Figs. 1-6 se usó la función $\mathrm{Y}=X^{2}, \mathrm{Xi}=10, \mathrm{Xf}=20, \mathrm{DAP} 1 \mathrm{E}=10^{\circ}, \mathrm{rE}=75^{\circ}$, $\mathrm{rS}=200$. Para las diferentes posiciones se usaron las ecs. 1-18.

$$
\begin{aligned}
& X_{1}=0.5\left(X_{i}+X_{f}\right)+0.5\left(X_{f}-X_{i}\right) c 157.5^{\circ} \\
& X_{2}=0.5\left(X_{i}+X_{f}\right)+0.5\left(X_{f}-X_{i}\right) c 112.5^{\circ} \\
& X_{3}=0.5\left(X_{i}+X_{f}\right)+0.5\left(X_{f}-X_{i}\right) c 67.5^{\circ} \\
& X_{4}=0.5\left(X_{i}+X_{f}\right)+0.5\left(X_{f}-X_{i}\right) c 22.5^{\circ} \\
& X_{B}=X_{1}+1\left(X_{2}-X_{1}\right) 0.25 \\
& X_{C}=X_{1}+2\left(X_{2}-X_{1}\right) 0.25 \\
& X_{H}=X_{1}+3\left(X_{2}-X_{1}\right) 0.25 \\
& X_{K}=X_{2}+1\left(X_{3}-X_{2}\right) 0.25 \\
& X_{N}=X_{2}+2\left(X_{3}-X_{2}\right) 0.25 \\
& X_{Q}=X_{2}+3\left(X_{3}-X_{2}\right) 0.25 \\
& X_{U}=X_{3}+1\left(X_{4}-X_{3}\right) 0.25 \\
& X_{V}=X_{3}+2\left(X_{4}-X_{3}\right) 0.25 \\
& X_{W}=X_{3}+3\left(X_{4}-X_{3}\right) 0.25 \\
& P_{i j} E=r E\left(X_{j}-X_{i}\right) \div r X \\
& Y_{j}=\left(X_{j}\right)^{2} \\
& P_{i j} S=r S\left(Y_{j}-Y_{i}\right) \div r Y \\
& P_{1 j} E=P_{i j} E-P_{i 1} E \\
& P_{1 j} S=P_{i j} S-P_{i 1} S
\end{aligned}
$$

Los valores de los parámetros, correspondientes a las diferentes imágenes de posiciones, se muestran en la Tabla 2. 


\begin{tabular}{|c|r|r|r|r|r|r|}
\hline $\mathbf{j}$ & \multicolumn{1}{|c}{$\mathbf{X j}$} & \multicolumn{1}{c}{ PijE } & \multicolumn{1}{l}{$\mathbf{Y j}$} & \multicolumn{1}{l|}{ PijS } & \multicolumn{1}{l|}{ P1jE } & \multicolumn{1}{c|}{ P1jS } \\
\hline i & 10.0 & 0.0 & 100.0 & 0.0 & -2.9 & -5.2 \\
\hline 1 & 10.4 & 2.9 & 107.8 & 5.2 & 0.0 & 0.0 \\
\hline B & 11.1 & 7.9 & 122.3 & 14.8 & 5.1 & 9.7 \\
\hline C & 11.7 & 13.0 & 137.7 & 25.1 & 10.1 & 19.9 \\
\hline H & 12.4 & 18.1 & 154.0 & 36.0 & 15.2 & 30.8 \\
\hline 2 & 13.1 & 23.1 & 171.3 & 47.5 & 20.3 & 42.3 \\
\hline K & 14.0 & 30.3 & 197.2 & 64.8 & 27.5 & 59.6 \\
\hline N & 15.0 & 37.5 & 225.0 & 83.3 & 34.6 & 78.2 \\
\hline Q & 16.0 & 44.7 & 254.6 & 103.1 & 41.8 & 97.9 \\
\hline 3 & 16.9 & 51.9 & 286.1 & 124.0 & 49.0 & 118.9 \\
\hline U & 17.6 & 56.9 & 309.4 & 139.6 & 54.1 & 134.4 \\
\hline V & 18.3 & 62.0 & 333.7 & 155.8 & 59.1 & 150.6 \\
\hline W & 18.9 & 67.1 & 358.8 & 172.6 & 64.2 & 167.4 \\
\hline 4 & 19.6 & 72.1 & 384.9 & 189.9 & 69.3 & 184.8 \\
\hline f & 20.0 & 75.0 & 400.0 & 200.0 & 72.1 & 194.8 \\
\hline
\end{tabular}

Tabla 2 Posiciones de eslabones

Fuente: Elaboración Propia

Usando las posiciones de precisión $\mathrm{P} 12 \mathrm{E}=$ 20.3, $\mathrm{P} 13 \mathrm{E}=49.0, \mathrm{P} 14 \mathrm{E}=69.3$ y DAP1E $=75^{\circ}$; se determinaron las posiciones siguientes:

$\mathrm{P}_{2} \mathrm{E}=D A P_{1} E+P_{12} E$

$\mathrm{P}_{3} \mathrm{E}=D A P_{1} E+P_{13} E$

$\mathrm{P}_{4} \mathrm{E}=D A P_{1} E+P_{14} E$

Para j=1, 2, 3, 4; se resolvió los sistemas de ecuaciones siguientes:

$\mathrm{L}_{1} \mathrm{CP}_{\mathrm{j}} \mathrm{E}+\mathrm{L}_{2} \mathrm{P}_{1 \mathrm{j}} \mathrm{ScP}_{\mathrm{j}} \mathrm{E}+\mathrm{L}_{3} \mathrm{SP}_{\mathrm{j}} \mathrm{E}-\mathrm{L}_{4}=\mathrm{P}_{1 \mathrm{j}} \mathrm{S}$

$\mathrm{M}_{1} \mathrm{CP}_{\mathrm{j}} \mathrm{E}+\mathrm{M}_{2} \mathrm{P}_{1 \mathrm{j}} \mathrm{ScP}_{\mathrm{j}} \mathrm{E}+\mathrm{M}_{3} \mathrm{SP}_{\mathrm{j}} \mathrm{E}-\mathrm{M}_{4}=$ $\left(P_{1 j} S\right)^{2}$

Donde $L_{1}, L_{2}, L_{3}, L_{4}$ y $M_{1}, M_{2}, M_{3}, M_{2}$ son términos correspondientes a las ecuaciones de compatibilidad del sistema; con los que se determinó:

$\Delta=\left(\mathrm{M}_{2}-2 \mathrm{~L}_{1}\right)^{2}+8 \mathrm{M}_{1} \mathrm{~L}_{2}$

$\lambda=\left(2 \mathrm{~L}_{1}-\mathrm{M}_{2}+\sqrt{\Delta}\right) \div\left(2 \mathrm{~L}_{2}\right)$

$\lambda=\left(2 \mathrm{~L}_{1}-\mathrm{M}_{2}-\sqrt{\Delta}\right) \div\left(2 \mathrm{~L}_{2}\right)$

Con $F_{1}, F_{2}, F_{3}, F_{4}$ en función de los parámetros de diseño; DE, DT, O, P1S; para cada $\lambda$, con las ecs. (27) - (34), se calculó:

$\mathrm{F}_{1}=\lambda \mathrm{L}_{1}+\mathrm{M}_{1}$

$\mathrm{F}_{2}=\lambda \mathrm{L}_{2}+\mathrm{M}_{2}$

$\mathrm{F}_{3}=\lambda \mathrm{L}_{3}+\mathrm{M}_{3}$

$\mathrm{F}_{4}=\lambda \mathrm{L}_{4}+\mathrm{M}_{4}$

$\mathrm{DE}=F_{2} \div 2$

$\mathrm{P}_{1} \mathrm{~S}=\lambda \div 2$

$\mathrm{O}=\mathrm{F}_{3} \div \mathrm{F}_{2}$

$\mathrm{DT}=\sqrt{\left(\mathrm{P}_{1} \mathrm{E}\right)^{2}+(\mathrm{O})^{2}+\left(\mathrm{P}_{1} \mathrm{~S}\right)^{2}-\mathrm{F}_{4}}$
Se sintetizo el mecanismo correspondiente a la Tabla 2 y Figs. 1 a 6; para $Y=X^{2}, X_{i}=10$, $X_{f}=20, \quad \mathrm{rE}=75^{\circ}, \quad \mathrm{rS}=200, \quad \mathrm{DAP} 1 \mathrm{E}=10^{\circ}$; obteniendo la solución para la raíz negativa de $\lambda$ indicada en la Tabla 3.

\begin{tabular}{|c|c|c|c|}
\hline DE & \multicolumn{1}{c}{ DT } & \multicolumn{1}{c|}{ O } & \multicolumn{1}{c|}{ P1S } \\
\hline-203.6 & 398.5 & -169.5 & 174.7 \\
\hline
\end{tabular}

Tabla 3 Parámetros de diseño

Fuente: Elaboración Propia

Al ser negativa la dimensión del eslabón de entrada (DE), la posición 1 del eslabón de entrada $(\mathrm{P} 1 \mathrm{E})$ será $10+180=190^{\circ}$. En caso contrario será $10^{\circ}$.

\section{Eslabones}

Los eslabones se generaron usando un paquete gráfico, se dimensionaron con parámetros. El fijo se muestra en la Fig. 7. Tiene un espesor de 0.025(DAE+DT); de su canal la profundidad es 0.0125(DAE+DT), el ancho es 0.1(DAE+DT) y su longitud es 2.4(DAE+DT); el diámetro de su orificio pasado (al centro) es 0.005 (DAE+DT).

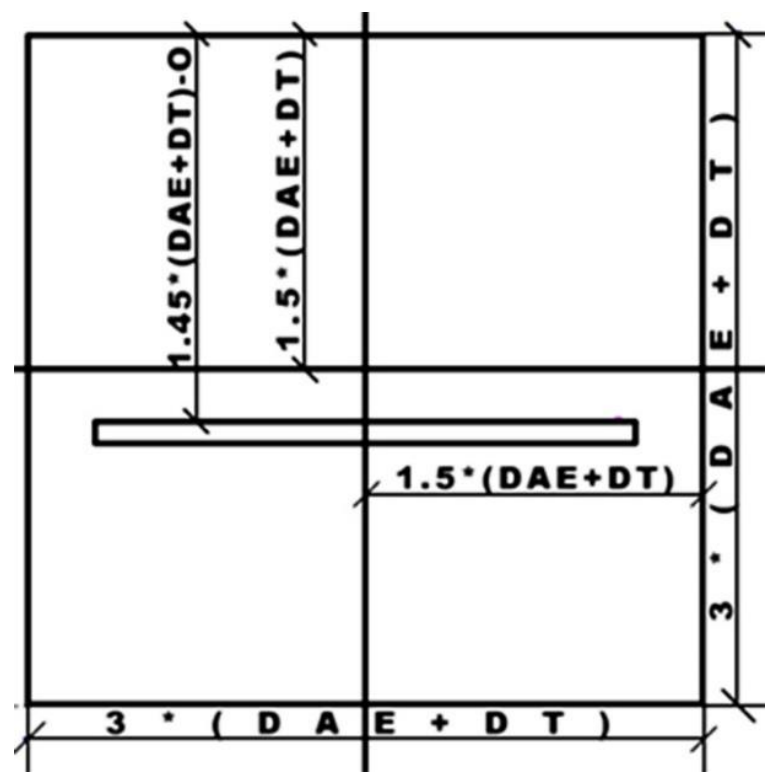

Figura 7 Eslabón fijo. Fuente: Elaboración Propia.

En las Figs. 8 a 10 se muestra los eslabones de entrada, trasmisor y salida. Para los orificios de los eslabones de entrada, trasmisor y de salida; se usó el mismo diámetro utilizado para el orificio del eslabón fijo. Los espesores de eslabones de entrada y trasmisor son de 0,0125(DAE+DT). El espesor del eslabón de salida es $0.025(\mathrm{DAE}+\mathrm{DT})$. 


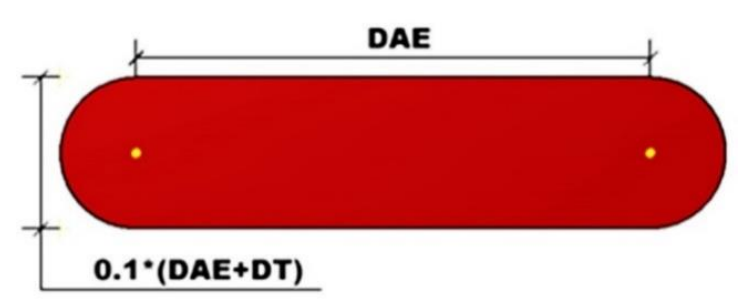

Figura 8 Eslabón de entrada Fuente: Elaboración Propia

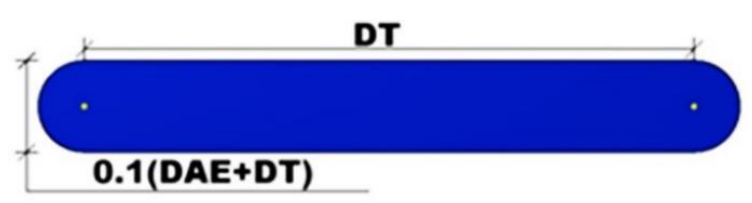

Figura 9 Eslabón trasmisor Fuente: Elaboración Propia

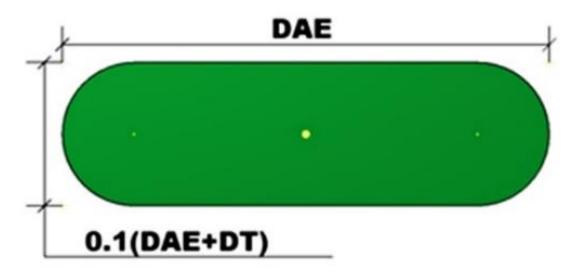

Figura 10 Eslabón de salida Fuente: Elaboración Propia

Todos los archivos de eslabones se vincularon a una y sólo una hoja electrónica de cálculo, con parámetros de la Tabla 1 para controlarlos.

\section{Mecanismo}

Para su control se usó la misma hoja electrónica de cálculo usada para el control de los eslabones. Se instaló el eslabón fijo, al cual se le eliminaron todos sus grados de libertad. El eslabón de entrada se instaló en segundo lugar; haciendo coincidir su superficie inferior con la superior del fijo; se declaró coaxiales el eje de uno de sus orificios, con el eje del orificio del eslabón fijo; para su rotación controlada se instaló un ángulo dirigido cero, de su eje de simetría longitudinal, con respecto al eje horizontal central del eslabón fijo. En tercer lugar; se instaló el eslabón de salida; haciendo coincidir su superficie inferior, con la superficie en el fondo del canal del fijo; también se hicieron coincidentes una de sus caras laterales planas, con una de las paredes del canal en el fijo; puesto que hay dos opciones de cierre de circuito, con raíz positiva o raíz negativa, se estableció una separación igual a P1S entre su plano de simetría y el plano de simetría del fijo, con lo que se asegura el cierre de circuito deseado.
En último lugar se instaló el eslabón acoplador; se hicieron coincidentes, su superficie inferior con la superior del eslabón de entrada; el eje de uno de sus orificios se declaró coaxial con el eje del orificio en el eslabón de salida; el eje de su otro orificio, se declaró coaxial con el eje del barreno libre del eslabón de entrada. En la Fig. 11 se muestra el mecanismo ensamblado en tres dimensiones. Puede observarse por qué el espesor del eslabón de salida, es el doble del espesor del eslabón de entrada. Si consideramos el fondo del canal como planta baja, el eslabón de entrada está en el primer piso, el eslabón trasmisor está en el segundo piso y el eslabón de salida está tanto en la planta baja como en el primer piso.

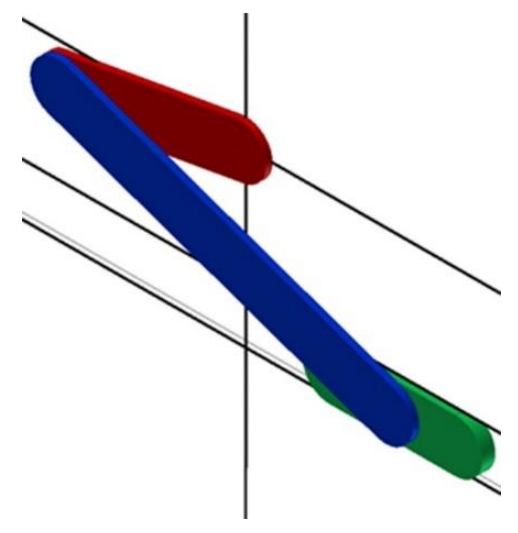

Figura 11 Mecanismo 3D

Fuente: Elaboración Propia

\section{Diseños}

La hoja electrónica de cálculo es tal que permite; cambiar todos o sólo algunos de los parámetros conocidos y seleccionados, en combinación cualquiera, siguientes: la función, Xi, Xf, DAP1E, rE, rS actualizando DE, DT, O, P1S; haciendo posible la actualización de los eslabones y del mecanismo. Para la descripción de diferentes diseños; se consideró invariantes los parámetros conocidos: función (cuadrática), $\mathrm{Xi}=10, \mathrm{Xf}=20$ y los parámetros seleccionados: $\mathrm{rE}=75^{\circ}$ y rS=200; variando sólo el parámetro seleccionado DAP1E; se muestran resultados en la Tabla 4.

\begin{tabular}{|r|r|r|r|r|}
\multicolumn{1}{|c|}{ DAP1E } & \multicolumn{1}{c|}{ DE } & \multicolumn{1}{c|}{ DT } & \multicolumn{1}{c|}{ O } & \multicolumn{1}{c|}{ P1S } \\
\hline 10.0 & -203.6 & 398.5 & -169.5 & 174.7 \\
\hline 30.0 & -187.8 & 251.1 & -117.5 & 87.3 \\
\hline 200.0 & 58.2 & 230.5 & 172.4 & -181.9 \\
\hline 180.0 & 210.2 & 454.7 & -205.3 & 195.5 \\
\hline 34.0 & -83.9 & 91.3 & 6.9 & -143.3 \\
\hline
\end{tabular}

Tabla 4 Diseños

Fuente: Elaboración Propia 
De los diseños; los tres primeros corresponden a soluciones con raíz negativa, los dos últimos corresponden a soluciones con raíz positiva. En la Fig. 1 se mostró el primero de los diseños, los restantes se muestran en las Figs. 12 a 15. Todos cumplen teóricamente con los requerimientos de diseño. El primero es Grashof, prácticamente cumple con los requerimientos de diseño y el rango total de movimiento de su eslabón de salida incluye rS.

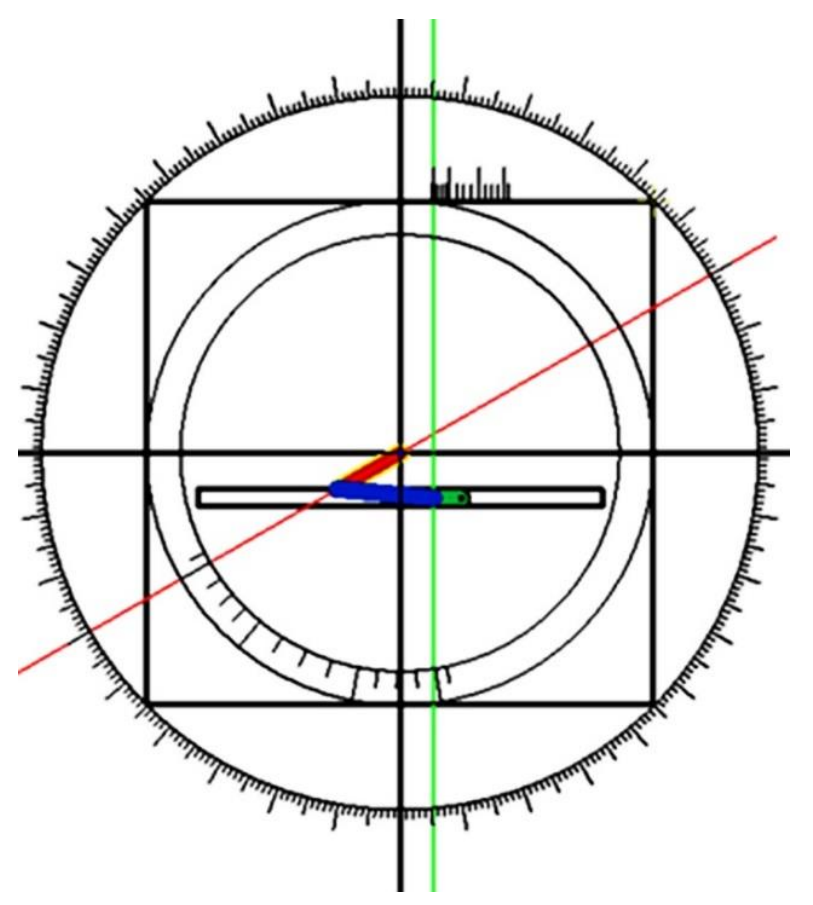

Figura 12 Segundo diseño

Fuente: Elaboración Propia

El segundo diseño no es Grashof, el rango total de movimiento de su eslabón de salida incluye rS. Sería una solución práctica siempre que el eslabón de entrada se conecte a un controlador lógico programable. Lo anterior debido a que su eslabón de entrada, al no tener la posibilidad de girar los 360 grados, se transformaría de manivela en oscilador.

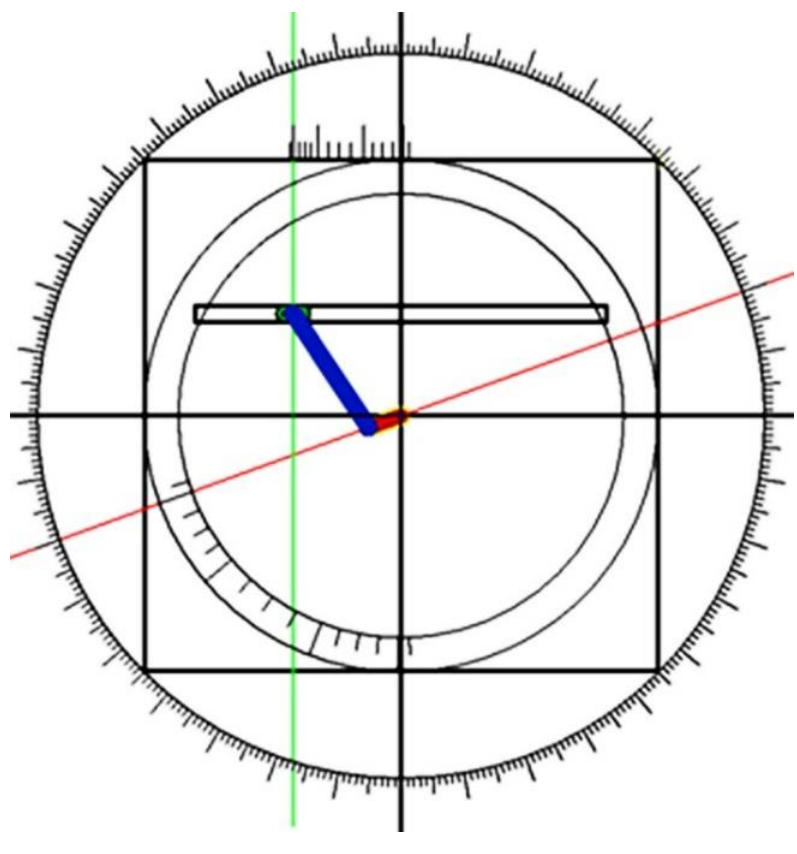

Figura 13 Tercer diseño Fuente: Elaboración Propia

El tercer diseño si es Grashof. El rango total de movimiento de su eslabón de salida no incluye rS; debido a que al sobreponerse el eslabón trasmisor al eslabón de entrada, el eslabón de salida estará en su posición extrema derecha entre su posición $\mathrm{W}$ y 4 . No es una solución práctica.

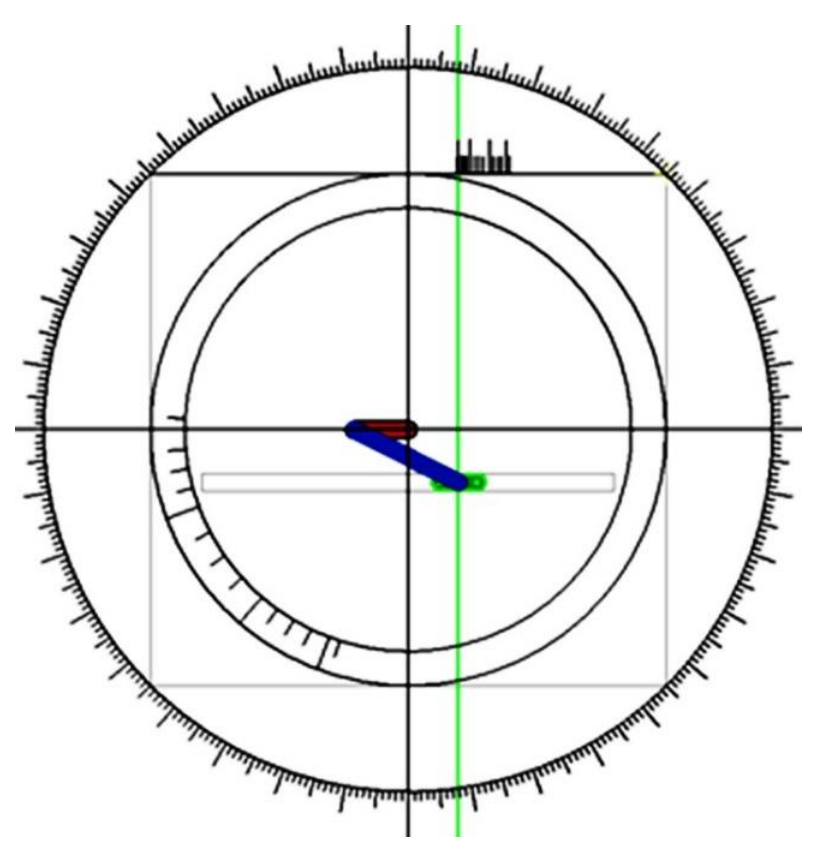

Figura 14 Cuarto diseño

Fuente: Elaboración Propia

El cuarto diseño si es Grashof, el rango total de movimiento de su eslabón de salida incluye rS y sería una solución práctica. 


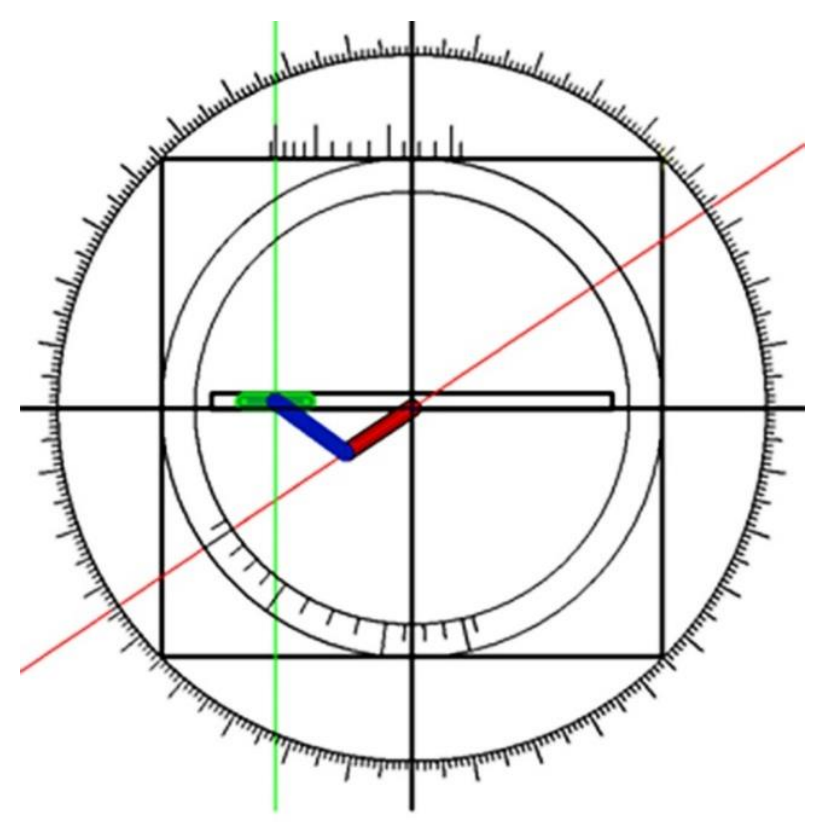

Figura 15 Quinto diseño Fuente: Elaboración Propia

El quinto diseño si es Grashof. El rango total de movimiento de su eslabón de salida no incluye rS; debido a que al sobreponerse el eslabón trasmisor al eslabón de entrada, el eslabón de salida estará en su posición extrema derecha entre su posición $\mathrm{U}$ y $\mathrm{V}$. No es una solución práctica.

\section{Análisis comparativo}

Descartados los diseños tercero y quinto; se evaluaron los porcentajes de desviación promedio para el primero, segundo y cuarto. Aceptando las posiciones del eslabón de entrada como exactas, por corresponder al parámetro independiente, las desviaciones entre posiciones teóricas y reales del eslabón de salida conducen a los porcentajes de desviación mostrados en la Tabla 5.

\begin{tabular}{|l|r|}
\hline Diseño & Desviación en \% \\
\hline Primero & 0.245 \\
\hline Segundo & 0.644 \\
\hline Cuarto & 0.127 \\
\hline
\end{tabular}

Tabla 5 Porcentajes

Fuente: Elaboración Propia

Otros aspectos importantes para el diseño de mecanismos son; ventaja mecánica, ergonomía, instalación, operación, resistencia, economía, fabricación, mantenimiento. Se omiten por estar fuera del objetivo del presente trabajo.

\section{Simulación}

En la siguiente secuencia gráfica, se muestran imágenes de posiciones del cuarto diseño, para el cual el porcentaje de desviación fue menor. La restricción para ubicar el eslabón de salida sobre el canal en el fijo deberá eliminarse, para hacer posible la simulación con la restricción de ángulo dirigido entre ejes de los eslabones fijo y de entrada.

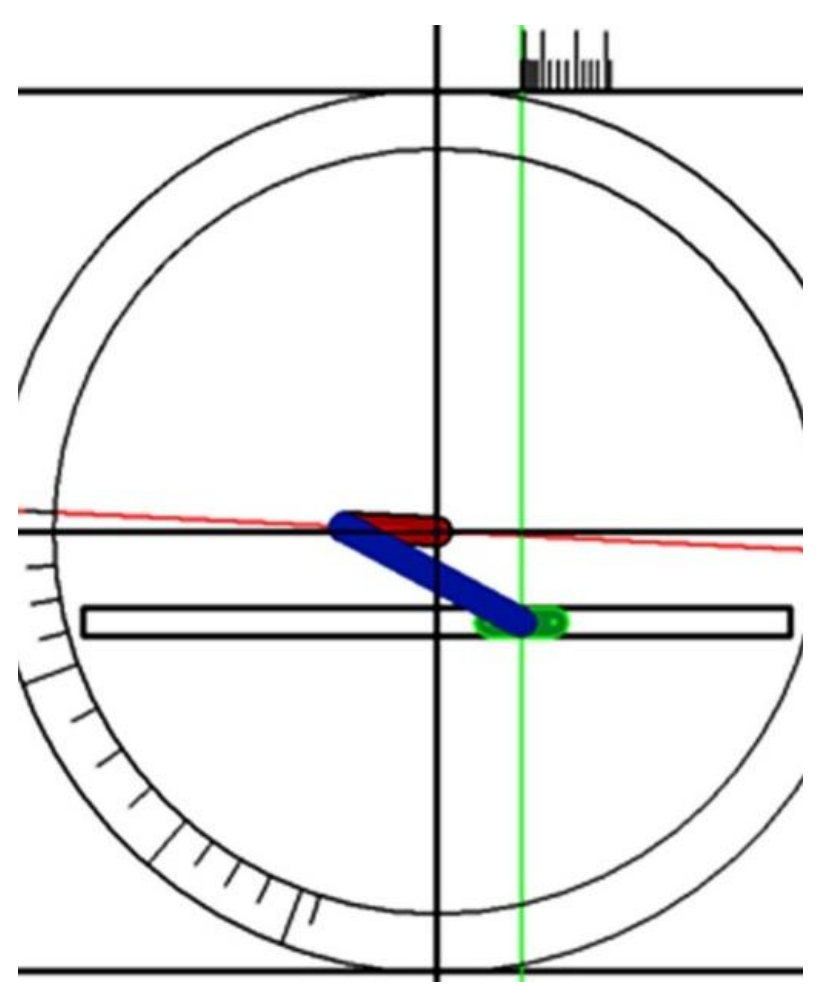

Figura 16 Posición i

Fuente: Elaboración Propia

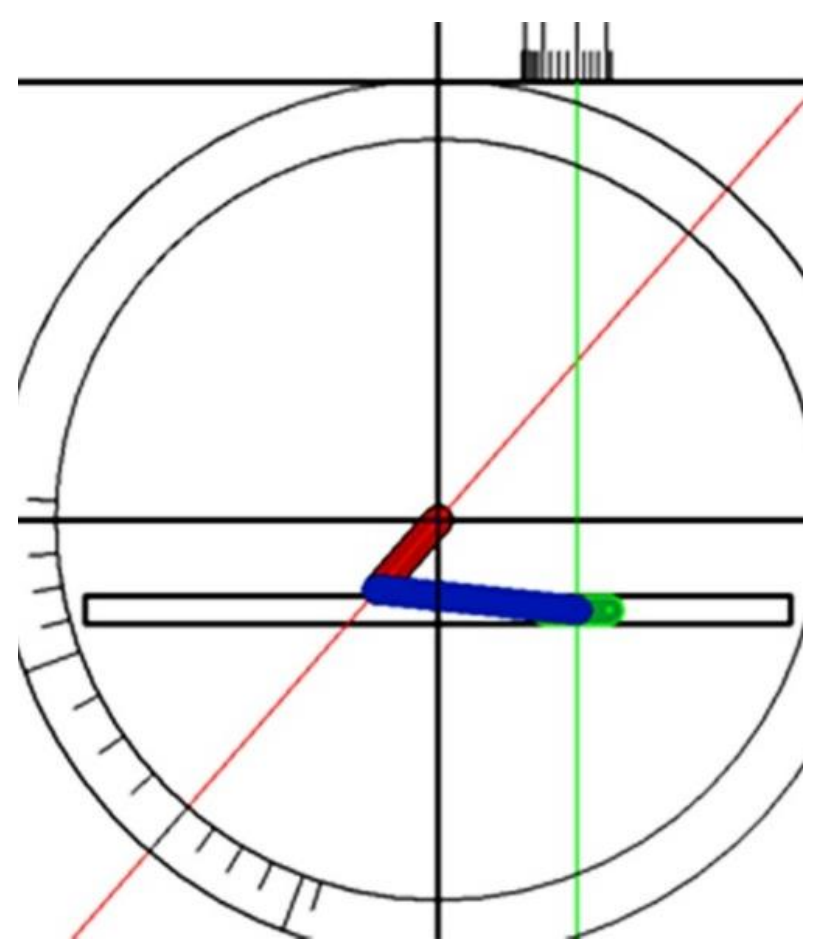

Figura 17 Posición 3

Fuente: Elaboración Propia 


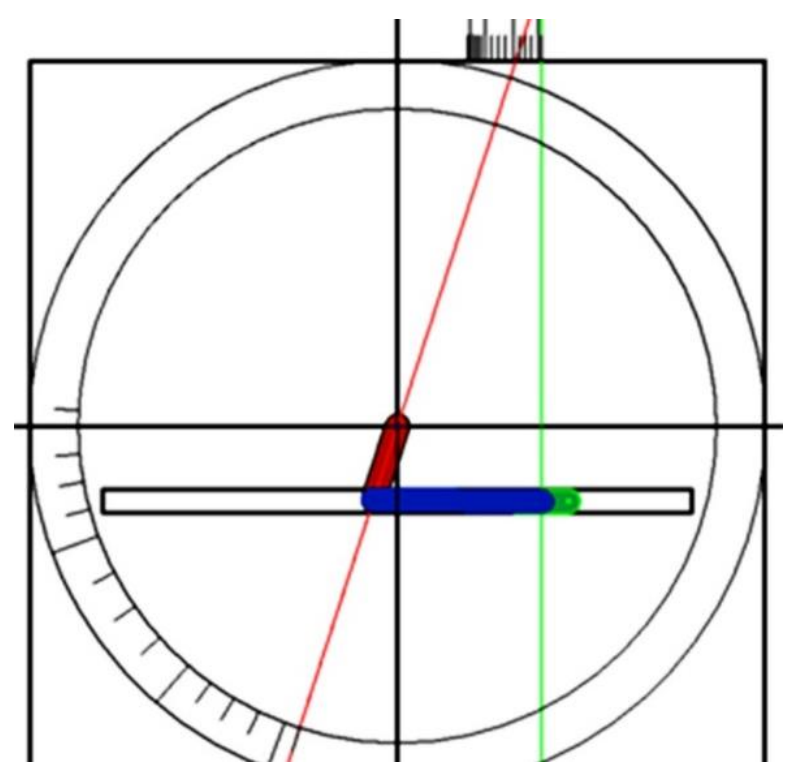

Figura 18 Posición $\mathrm{f}$ Fuente: Elaboración Propia

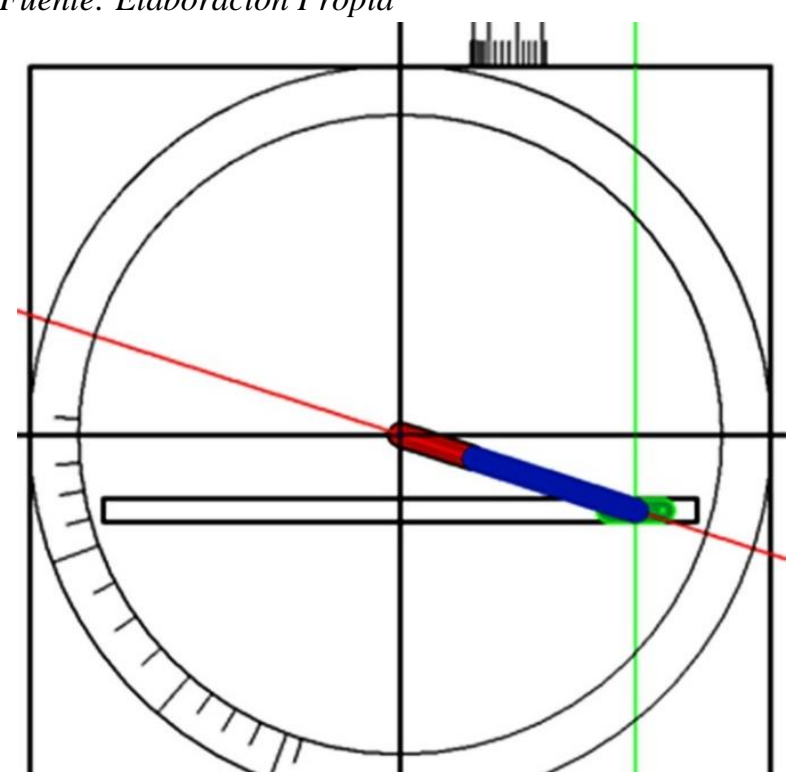

Figura 19 Límite derecho

Fuente: Elaboración Propia

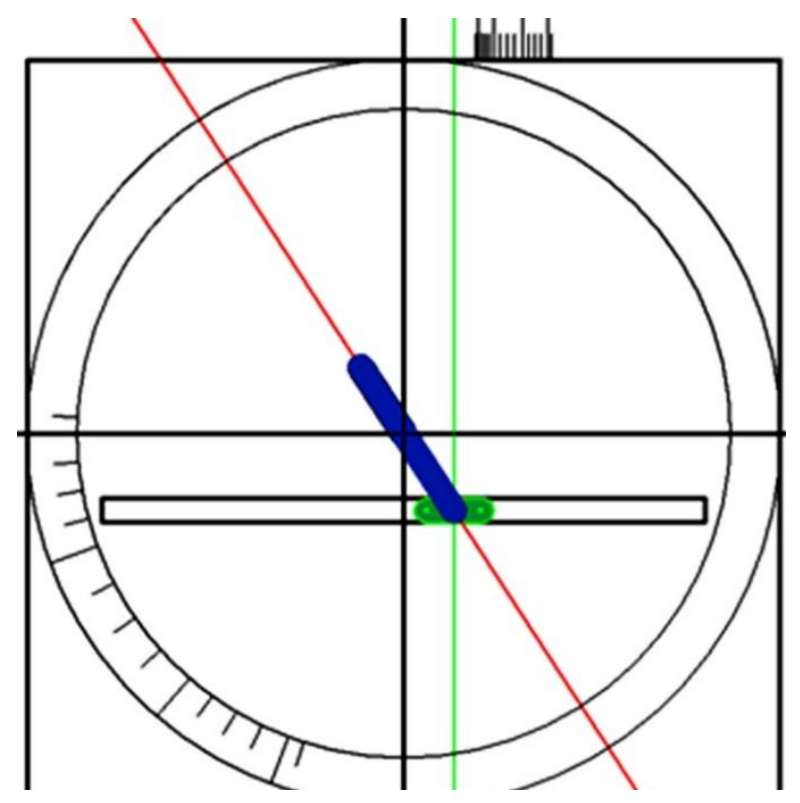

Figura 20 Límite izquierdo

Fuente: Elaboración Propia
Para demostrar que el proceso es amigable, rápido, seguro, exacto y paramétrico; se cambió, simultáneamente, los parámetros de entrada y seleccionados; $Y=\log (X), X_{i}=12, X_{f}=16$, $\mathrm{rE}=85^{\circ}, \mathrm{rS}=150, \mathrm{DAP} 1 \mathrm{E}=330^{\circ}$; constatando la actualización de los parámetros de diseño en la hoja electrónica de cálculo, así como de los eslabones y del mecanismo en los archivos gráficos; en la Tabla 6 y Figs. 21 a 26 se muestran resultados para la raíz positiva de $\lambda$.

\begin{tabular}{|c|c|c|c|}
\hline DE & DT & O & P1S \\
\hline 112.2 & 350.5 & -238.0 & -202.5 \\
\hline
\end{tabular}

Tabla 6 Mecanismo amigable Fuente: Elaboración Propia

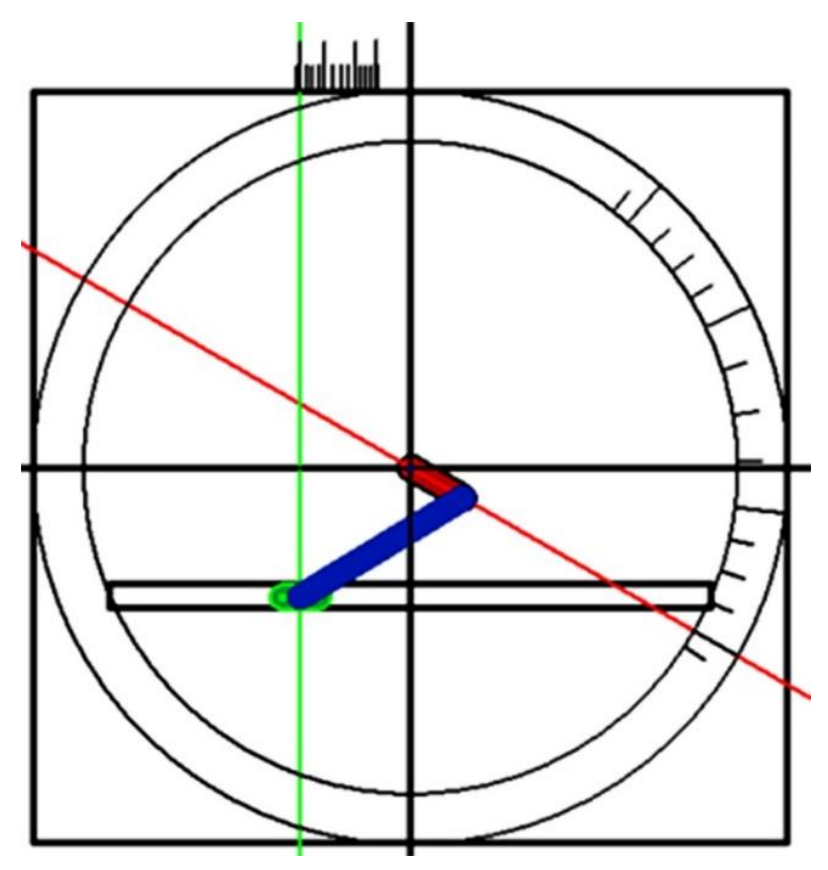

Figura $21 \mathrm{P} 1$

Fuente: Elaboración Propia

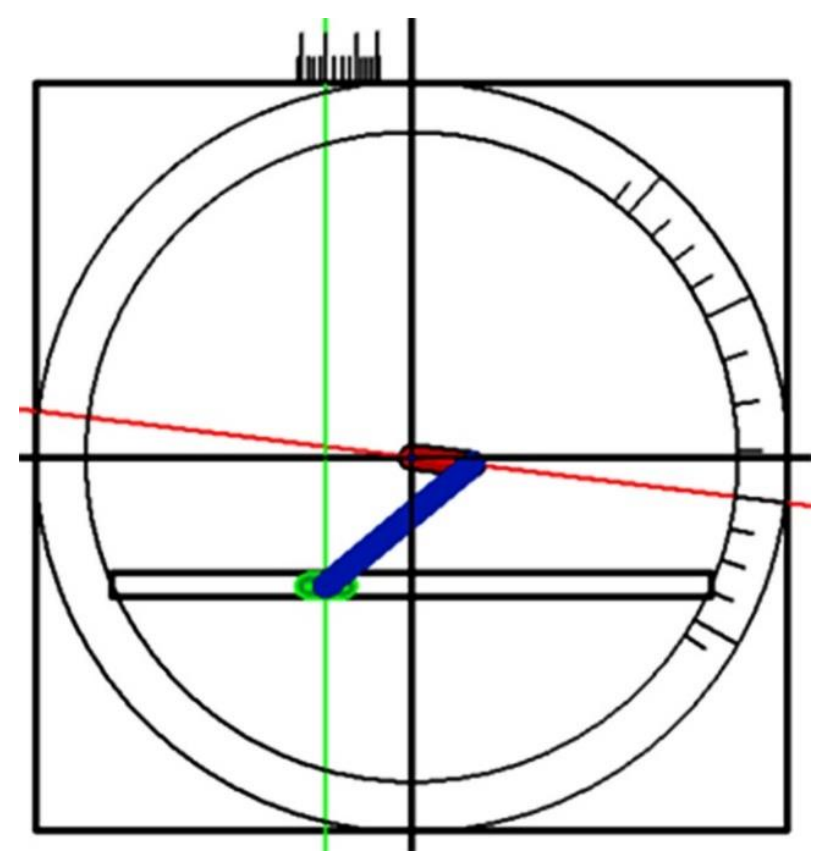

Figura $22 \mathrm{P} 2$

Fuente: Elaboración Propia

JIMÉNEZ-RABIELA, Homero, VAZQUÉZ-GONZÁLEZ, Benjamín, RAMÍREZ-CRUZ, José Luis y GARCÍA-SEGURA, Pedro. Mecanismo Diseñado y Simulado Virtualmente. Revista de Simulación y Laboratorio 2019. 


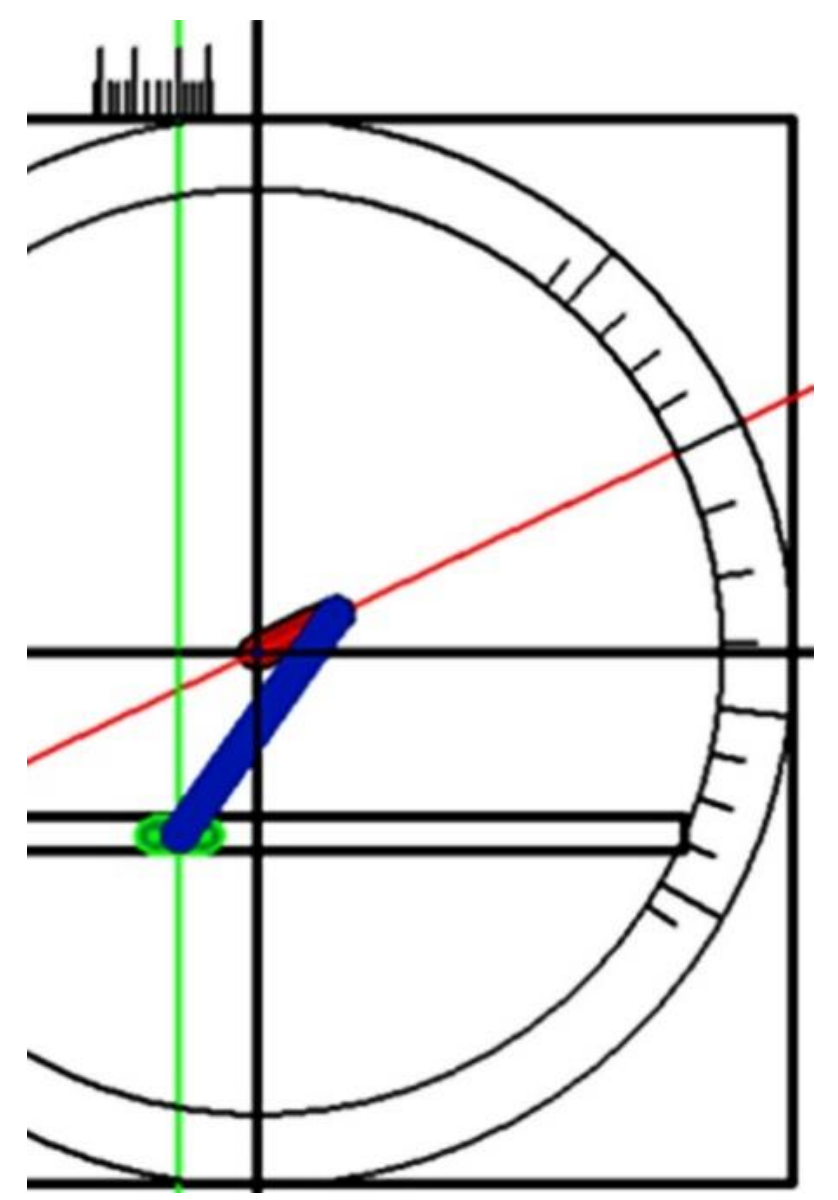

Figura $23 \mathrm{P} 3$

Fuente: Elaboración Propia

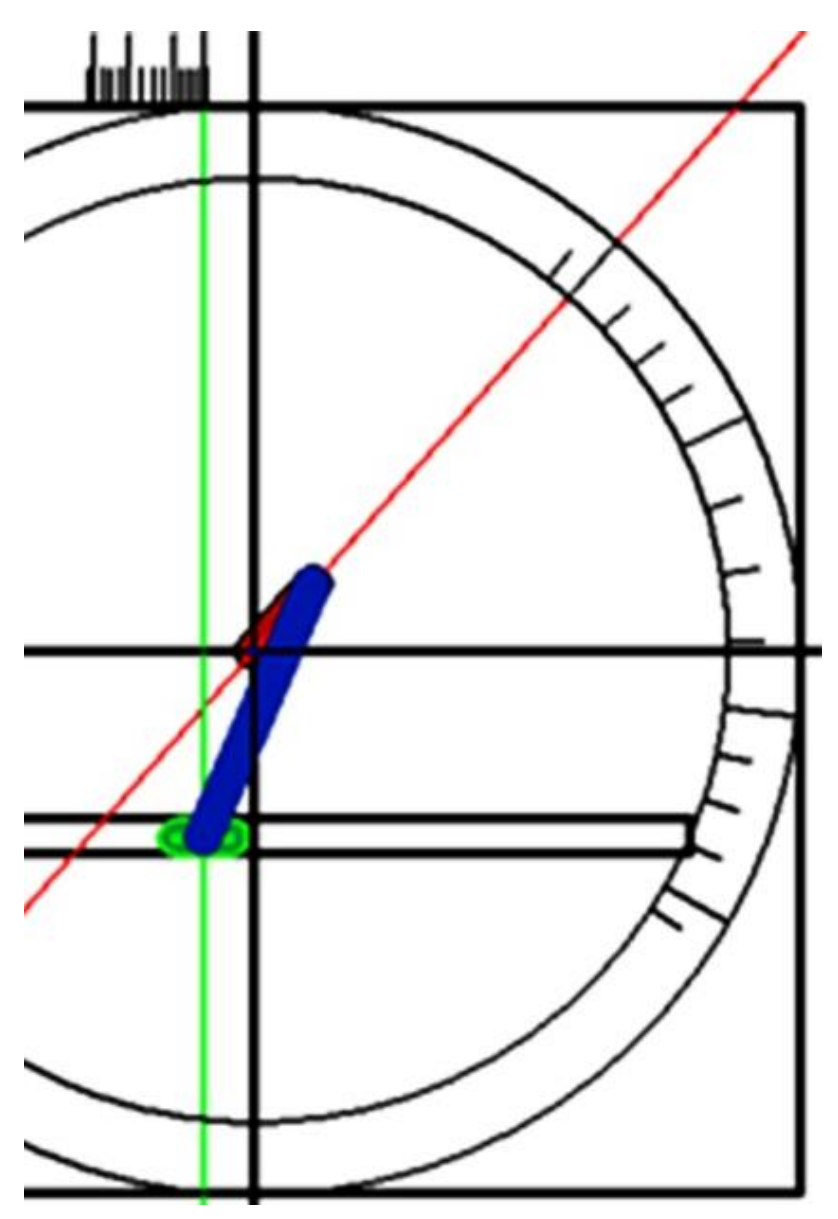

Figura $24 \mathrm{P} 4$

Fuente: Elaboración Propia

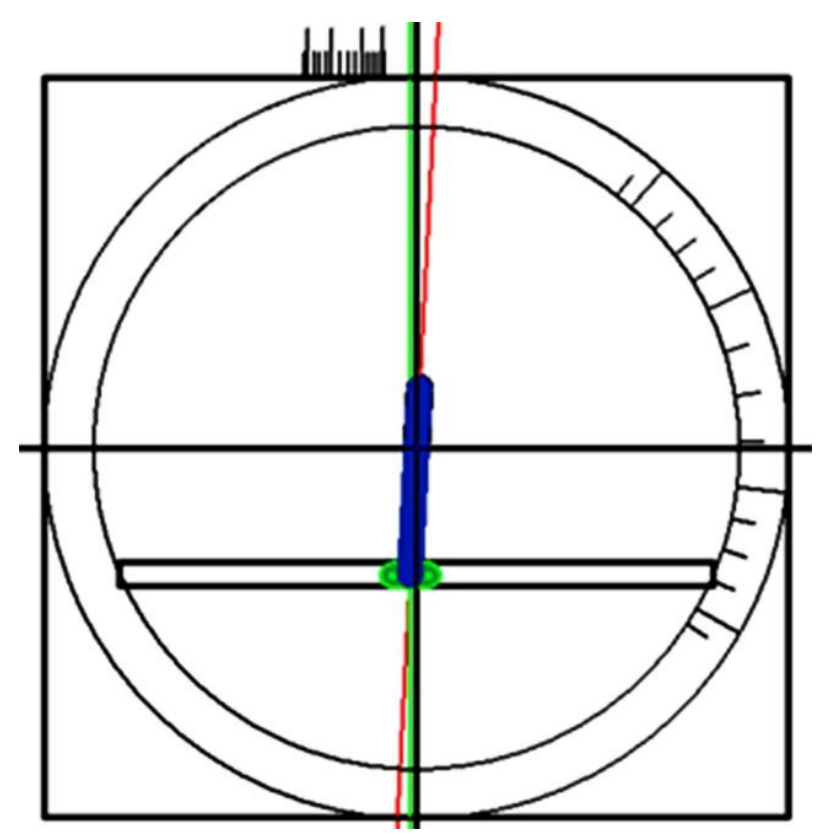

Figura 25 Extremo derecho Fuente: Elaboración Propia

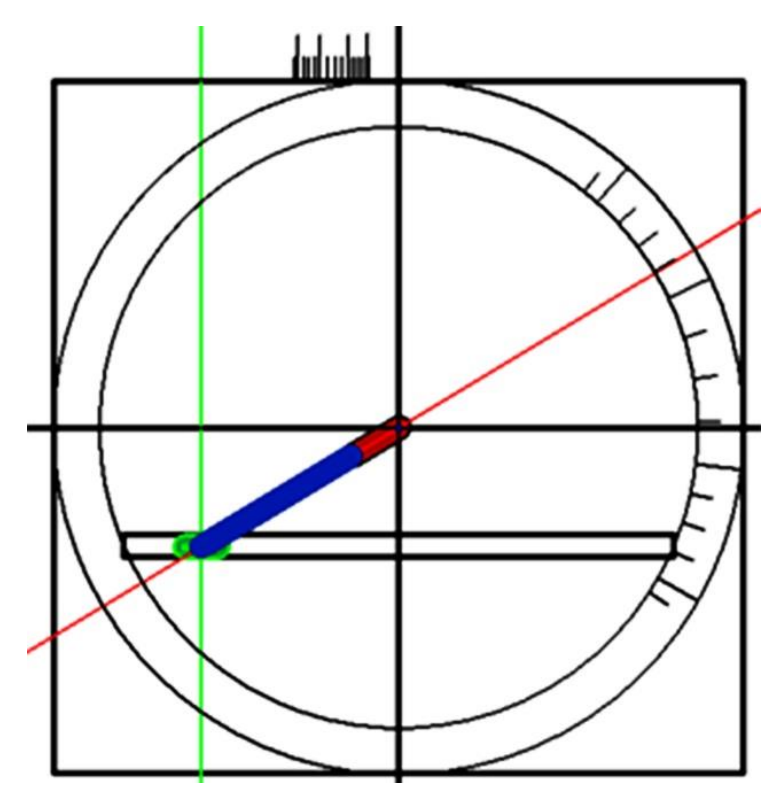

Figura 26 Extremo izquierdo

Fuente: Elaboración Propia

\section{Resultados}

Para diseñar, analizar, controlar, simular y evaluar el sistema; se estableció un reducido número (23) de parámetros. Los cálculos en hoja electrónica permitieron la actualización de los parámetros de diseño, para una cualquiera combinación de cambios en aquellos conocidos y seleccionados. La relación entre las diferentes dimensiones tanto lineales como angulares, de los eslabones en función de un número reducido de parámetros, permitió proporcionalidad entre los mismos. 
Conociendo la cinemática del sistema, se ensambló el mecanismo para obtener una posición dada para el eslabón de entrada, haciéndole corresponder a dos opciones de posición del eslabón de salida. Siendo un procedimiento amigable se generó un número considerable de diseños, sólo se presenta una parte de ellos. El análisis comparativo permitió valorar los diferentes diseños tanto desde el punto de vista cualitativo como cuantitativo. La simulación, posible del sistema, permitió evaluarlo desde la óptica particular del usuario.

\section{Conclusión}

Con base en resultados; el proceso descrito es amigable, rápido, seguro, exacto y paramétrico. Características que lo hacen recomendable para uso de catedráticos, empresarios, investigadores, profesionales y estudiantes.

\section{Agradecimiento}

Se agradece el apoyo institucional, logístico y financiero de la Universidad Autónoma Metropolitana y de la Unidad azcapotzalco, en particular de la División de Ciencias Básicas e Ingeniería y del Departamento de Energía.

\section{Referencias}

Alvarez J. C. \& Su H. J. (2012). an intuitive virtual environment for supporting the conceptual design of mechanisms. Abril 30, 2019, de VRMDS Sitio web: https://doi.org/10.1007/s10055-009-0144-z.

Becker M. C., Salvatore P. \& Zirpoli F. (2005). The impact of virtual simulation tools on problem-solving and new product development organization. ELSEVIER, 34, pp.1305-1321.

Chamba, J., Sánchez, M., Noroña, J., \& Franco, R. (2019). Motion simulation of a hexapod robot in virtual reality enviromments. Enfoque UTE, 10(1), 173-184.

Francisco, A. M., Fernández, D. L. M., \& Chua, J. H. (2019). Diseño, Desarrollo e Implementación de Recorrido Virtual en 3D como Fortalecimiento Académico y Tecnológico en Campus Universitario. Tecnología Educativa Revista CONAIC, 6(1), 713.
Hartenberg R. S. \& Denavit J. (1964). Kinematic Synthesis of Linkages. New York: Mc Graw Hill. López P. R. et al. (2012). Simulación de un Mecanismo Biela-Manivela-Corredera. abril 30, 2019, de Congreso Nacional de Mecatrónica Sitio web: 978-607-95347-7-6.

Rider, Michael J. (2015). Design and Analysis of Mechanisms a Planar Approach. United Kingdon. John Wiley \& Sons.

Robson N. \& Ghosh S. (2015). Geometric design of planar mechanisms based on virtual guides for manipulation. Abril 30, 2019, de VR Sitio web:

https://doi.org/10.1017/S0263574715000272.

Sánchez, J. P. C. (2019). Incremento de inmersividad en usuarios de entornos de realidad virtual utilizando una interfaz háptica para limitación de movimiento en dedos.

Schuler J., Ketchel J. \& Larochelle P. (2007). Computer-Aided Modeling and Manufacturing of Spherical Mechanisms via a novel Web Tool. Journal of Computation, 4, pp. 339-346. 